\title{
Combinations of Leaf Powders of Ruta Graveolens and Azadirachta indica to Enhance the Repellent Activity of Sitophilus zeamais (Motsch.) in Stored Maize in Sri Lanka
}

\author{
Perera A.G.W.U. ${ }^{1 *}$, Karunaratne M.M.S.C. ${ }^{1}$ and Chinthaka S.D.M. ${ }^{2}$ \\ ${ }^{I}$ Department of Zoology, University of Sri Jayewardenepura, Sri Lanka \\ ${ }^{2}$ Department of Chemistry, University of Sri Jayewardenepur, Sri Lanka \\ *wathsalauda@gmail.com
}

\begin{abstract}
Maize weevil (Sitophilus zeamais, Motsch.) is an utterly ubiquitous and cosmopolitan field-tostore insect pest with an economic importance of stored maize in tropical and sub-tropical regions of the world. Current renewed interest in replacing the synthetic insecticides has served as the impetus for the evaluation and intensification of eco-friendly anti-weevil measures such as the use of plant based post-harvest bio-insecticides. This study was therefore, designed to investigate the repellent potency of the leaf powders of Ruta graveolens and Azadirachta indica individually and in combinations of various proportions under ambient laboratory conditions against Sitophilus zeamais in both contact and vapour forms. For both plants, $50 \mathrm{~g}$ each of maize grains were mixed with leaf powders at different doses of 1.0, 3.0, 5.0, 7.0 and $10.0 \mathrm{~g}$ and the repellent rate was recorded within an hour of weevil introduction. The repellent potency of three combination ratios of 1:1,1:2 and 2:1 of $R$. graveolens and A. indica leaf powders incorporating into the dosage level of $10.0 \mathrm{~g}$ was evaluated at every 10 minute intervals up to an hour of weevil exposure. The highest contact repellent effect of leaf powders was produced by $R$. graveolens $(97 \pm 2.74 \%)$ followed by $A$. indica $(74 \pm 5.48 \%)$ whereas highest fumigation repellent effect of leaf powders was exhibiting by $R$. graveolens $(96 \pm 2.24 \%)$ followed again by $A$. indica $(47 \pm 2.74 \%)$ at the highest dosage of $10.0 \mathrm{~g}$ within an hour of weevil exposure when they were tested individually. All combinations repelled $S$. zeamais adults at a faster rate than when either powder was tested individually whilst the 2:1 combination of $R$. graveolens and $A$. indica exhibiting the highest repellent rates of $100 \%$ and $98 \%$ in both contact and vapor forms respectively within 50 minutes of post treatment thus increasing the repellent potential of the respective leaf powders to a great extent. The leaf powders of the two plants under present investigation revealed their improved grain protecting capability when used individually and in mixtures to be used as bio-rational and natural leads in large-scale protection of stored maize.
\end{abstract}

Keywords: Sitophilus zeamais, Ruta graveolens, Azadirachta indica, Repellency, Leaf powder 